\title{
Percepción del paisaje socioambiental agroecológico: trazos para el desarrollo humano en Tlajomulco de Zúñiga Jalisco, México
}

\author{
Percepção da paisagem socioambiental agroecológica: \\ contornos para o desenvolvimento humano em Tlajomulco \\ de Zúñiga Jalisco, México
}

Perception of the agroecological socio-environmental landscape: outlines for human development in Tlajomulco de Zúñiga Jalisco, Mexico

Paloma Gallegos Tejeda [a, b] [D, Pedro Lina Manjarrez [a] (iD)

[a] Instituto Politécnico Nacional (IPN), Centro Interdisciplinario de Investigaciones y Estudios sobre Medio Ambiente

y Desarrollo (CIIEMAD), Ciudad de México, México

[b] Universidad de Guadalajara, Guadalajara, México

Cómo citar: Tejeda, P. G., \& Manjarrez, P. L. (2021). Percepción del paisaje socioambiental agroecológico: trazos para el desarrollo humano en Tlajomulco de Zúñiga Jalisco, México. urbe. Revista Brasileira de Gestão Urbana, v.13,

e20210083. https://doi.org/10.1590/2175-3369.013.e20210083

\section{Resumen}

El municipio de Tlajomulco de Zúñiga ha sido transformado, en las últimas décadas, por los procesos de conurbación en la metrópoli de Guadalajara, Jalisco México, deteriorando su entorno paisajístico, social y ambiental. El paisaje tradicional y rural cambia por el crecimiento urbano, con la pérdida de recursos naturales, productivos y culturales. Observar el entorno de los municipios en conurbación, desde la percepción del paisaje de sus habitantes, muestra los matices identitarios, participativos y de deterioro en la transición de zonas rurales a urbanas, así como la búsqueda de alternativas de desarrollo en el reconocimiento y conservación del paisaje agroecológico. La metodología para su interpretación es la lectura de imágenes del paisaje de los habitantes quienes desde temprana edad perciben las dimensiones paisajísticas del agua, comunidad, suelo y flora y fauna, en su relación con la sustentabilidad. El objetivo es aplicar una metodología que identifique los elementos de la traza del paisaje agroecológico para señalar las condiciones necesarias de su conservación patrimonial en el desarrollo humano y soberanía alimentaria. Las herramientas de valorización de la imagen reconocen los elementos que conforman al paisaje, desde la sistematización y clasificación de lo observado, hasta análisis y síntesis de la relación entre elementos percibidos.

Palabras clave: Percepción comunitaria. Recursos paisajísticos. Caracterización del paisaje. Agroecología y sustentabilidad. 


\section{Resumo}

O município de Tlajomulco de Zúñiga foi transformado, nas últimas décadas, por processos de conurbação na metrópole de Guadalajara, Jalisco México, causando uma deterioração de seu entorno socioambiental paisagístico. A paisagem tradicional e rural muda devido ao crescimento urbano com a perda de recursos naturais, produtivos e culturais. A observação do entorno dos municípios em conurbação, a partir da percepção da paisagem de seus habitantes, mostra as nuances identitárias, participativas e de deterioração na transição do meio rural para o urbano, bem como a busca por alternativas de desenvolvimento no reconhecimento e na conservação da paisagem agroecológica. A metodologia para sua interpretação é a leitura de imagens da paisagem dos moradores do lugar que, a partir dos quatro anos, percebem as dimensões paisagísticas de água, comunidade, solo e flora e fauna, em sua relação com a sustentabilidade. O objetivo é aplicar uma metodologia para identificar os elementos que compõem o traçado da paisagem agroecológica para indicar as condições necessárias de conservação do seu patrimônio para o desenvolvimento humano e segurança alimentar. Ferramentas de valorização da paisagem reconhecem os elementos que compõem sua imagem para a sistematização e classificação do que é observado, até a análise e síntese da relação entre os elementos percebidos.

Palavras-chave: Percepção da comunidade. Recursos da paisagem. Caracterização da paisagem. Agroecologia e sustentabilidade.

\section{Abstract}

The municipality of Tlajomulco de Zúniga has been transformed, in recent decades, by conurbation processes in the metropolis of Guadalajara, Jalisco Mexico, causing a deterioration of its social and environmental landscape. The traditional and rural landscape changes due to urban growth with the loss of natural, productive, and cultural resources. Observing the environment of the municipalities in conurbation, from the perception of the landscape of its inhabitants, shows the identity, participatory and deterioration nuances in the transition from rural to urban areas, as well as the search for development alternatives in the recognition and conservation of the agroecological landscape. The methodology for its interpretation is the reading of images of the landscape of the inhabitants of the place who, from early age, perceive the landscape dimensions of water, community, soil and flora and fauna, in their relationship with sustainability and food sovereignty. The objective is to apply a methodology for identify the elements that make up the layout of the agroecological landscape to indicate the conditions of its necessary heritage conservation in human development. Landscape valorization tools recognize an image of the landscape elements that make up for the systematization and classification of what is observed, up to the analysis and synthesis of the relationship between perceived elements.

Keywords: Community perception. Landscape resources. Landscape characterization. Agroecology and sustainability.

\section{Introducción}

El proceso de conurbación en el municipio de Tlajomulco hace que el paisaje rural se transforme en un paisaje periurbano del Área Metropolitana de Guadalajara (AMG), constituido por unidades habitacionales que contrastan con las amplias parcelas y el número de pequeñas huertas de productos hortícolas y plantas medicinales. Con ello, el territorio del paisaje agrícola enfrenta la presión constante de cambios de uso de suelo, primordialmente por los intereses inmobiliarios que se multiplican desde hace dos décadas, poniendo en riesgo las zonas agrícolas, áreas verdes y Áreas Naturales Protegidas (ANP).

Si bien el paisaje patrimonial agroecológico se convierte en un paisaje rural-urbano donde se reconoce la necesidad del acceso a los alimentos frescos y naturales. También es en esta transición territorial donde se conjugan distintas realidades que se enriquecen con la percepción de los habitantes.

Así, la metodología de percepción de imágenes del paisaje se establece y potencia con otras metodologías de caracterización del dibujo, como el análisis del discurso que conlleva distintos 
procedimientos de clasificación de los elementos observados, la elaboración de redes semánticas, y de correlación con indicadores como las dimensiones de la sustentabilidad, la armonía y la ruptura de la armonía. Con lo anterior, se aprecian dos posiciones teóricas-metodológicas la primera relacionada con la interpretación de los datos y la segunda la relación geografía-percepción y paisaje-percepción.

En relación con la percepción del paisaje, el caso suizo, con la "Guía de planificación y desarrollo de proyectos, desarrolla el Esthetique d'un Paysage (Estética de un Paisaje) donde se explican métodos de apreciación del paisaje de forma intuitiva que, analizan las características emocionales y sensoriales del paisaje" (Aponte-García et al., 2018, p. 53), de forma analítica permite conocer aspectos de la calidad del paisaje, hasta lograr la identificación de la vulnerabilidad, como elementos claves del proyecto de políticas públicas y trabajo.

A propósito, en la gestión del territorio, la evaluación visual del paisaje tiene importancia desde finales del siglo XX para actividades de planificación y de diseño de políticas públicas. Se destaca el uso de "indicadores eco-estéticos" donde se conjugan las preferencias visuales, de quienes viven el paisaje y teorizan y conceptualizan al paisaje como objeto de estudio. De esta forma, se establecen las bases para la percepción e interpretación socio ambiental y cultural del espacio del paisaje (López-Contreras et al., 2019).

Aunque destacan los elementos naturales el objetivo de la percepción espacial que plantea AponteGarcía et al. en 2018 es "encontrar como se relacionan las personas con los paisajes percibidos y cuáles son sus reacciones frente a ellos, la importancia y valoración que les otorgan, y cómo se ven influidos por ellos hasta reflejarlos en su comportamiento" (p. 57). Además, explica que la "lectura humana del paisaje como totalidad, va más allá de cuestiones técnicas, [...] ya que caracterizar el paisaje demanda [...] detallar sus características y establecer categorías [...] asumiendo las relaciones tangible o intangible [...] con las emociones" (p. 58).

La importancia de la percepción del paisaje radica en que ayuda a expresar el conocimiento de la población sobre su territorio, en este caso se manifiestan las condiciones de los recursos naturales, actividades productivas y la conservación, lo que sigue es el argumento de Ramos (2007, citado en PeraltaRivero et al., 2016) "Ese reconocimiento e interrelación por parte de los actores locales inmersos en esta dinámica, es uno de los elementos más poderosos a la hora de toma de decisiones sobre los recursos naturales de sus comunidades" (p.72).

La exploración de la percepción del paisaje de Tlajomulco de Zúñiga con una perspectiva transgeneracional (desde los cuatro años en adelante), explora la interpretación de distintas visiones donde se exprese el entorno desde el observador, busca el reconocimiento de los elementos paisajísticos, su relación con las dimensiones de la sustentabilidad, la armonía y ruptura de la armonía para llegar al encuentro del paisaje agroecológico y de desarrollo humano.

Al respecto, el objetivo del estudio de percepción es aplicar una metodología que ayude a reconocer los elementos paisajísticos agrícolas de Tlajomulco desde la sustentabilidad con la interpretación del paisaje agroecológico en relación con el desarrollo humano y la soberanía alimentaria para su conservación en la transición rural urbana.

\section{La percepción del paisaje: un acto creativo}

Observar al paisaje, como un proceso en constante cambio, muestra otra manera de entender cómo las personas lo crean y recrean. En este sentido, el Consejo Europeo, a través del Convenio Europeo del Paisaje 2000, lo define como "un área, percibida por las personas, cuyo carácter es el resultado de la acción e interacción de factores naturales y humanos" (Cruz et al., 2018, p. 4).

Ante el dinamismo del paisaje es pertinente citar su concepto establecido en la Iniciativa Latinoamericana del Paisaje 2012 -LALI, por sus siglas en inglés- "paisaje es un espacio/tiempo resultado de factores naturales y humanos, tangibles e intangibles que, al ser percibido y modelado por la gente, refleja la diversidad de las culturas" (Aponte-García et al., 2018, p. 47). De lo cual inferimos la trascendencia de explorar la percepción del paisaje desde los habitantes. 
Para profundizar en la valoración del paisaje se argumenta de Korff (2005, citado en Cruz et al., 2018) la relación entre percepción y paisaje, a través de "un proceso de interpretación humana, que ayuda a observar las dinámicas sociales y posibles desarmonías en el presente y futuro" (p. 3).

De manera que "la percepción y el recurso visual constituyen la base para una evaluación espacial, compositiva y simbólica del paisaje, con distintas escalas de análisis panorámica, intermedia y cercana o vivencial" (Aponte-García et al., 2018, p.56), experiencias de conocimiento a través de los sentidos desde lo visual, auditivo, olfativo y táctil.

Desde otra perspectiva, la percepción individual del paisaje, de acuerdo con Dos Santos (2005), es "un acto creativo que es influenciado por las características fisiológicas propias del ser humano, su carácter, personalidad y también por sus influencias sociales y culturales" (p. 417).

Así, la evaluación del impacto visual por el cambio en el paisaje viene a “...completar aspectos económicos que hasta ahora no suelen ser tenidos en cuenta en la planificación, ordenación y gestión de los espacios naturales y rurales, y que, concretamente está ausente en los estudios de impacto ambiental" (Álvarez-Farizo \& Figueiredo, 2008, p. 4).

En la investigación científica la información viene de diversos ámbitos académicos, institucionales, gubernamentales y no gubernamentales, con la idea de avanzar tanto en la perspectiva patrimonial como en la conservación del paisaje. Al respecto la evaluación del paisaje es interdisciplinaria, estableciendo unidades de análisis, unidades de paisaje, unidades ambientales, entre otras (Lina, 2012, p. 103).

\section{Metodología}

El proceso de investigación se llevó a cabo en las siguientes etapas. Primero, con la revisión documental y visitas al área de estudio, donde se caracterizaron los sitios relevantes del paisaje urbano, rural y paisaje agrícola de Tlajomulco de Zúñiga. En seguida, se diseñaron la estrategia y los instrumentos para la caracterización de la percepción del paisaje, a fin de aplicarse en un taller con la población de Tlajomulco.

Posteriormente, se procesó y sistematizó la información creando mapas, dibujos, tablas y diagramas. A continuación, se aplicó el análisis de percepción del paisaje, ubicando a los asistentes al taller en diferentes grupos de acuerdo con su edad (niños, adolescentes, jóvenes y adultos). Finalmente, se obtuvo un patrón de percepción colectiva del paisaje urbano rural agroecológico con implicaciones de desarrollo humano (Diagrama 1).

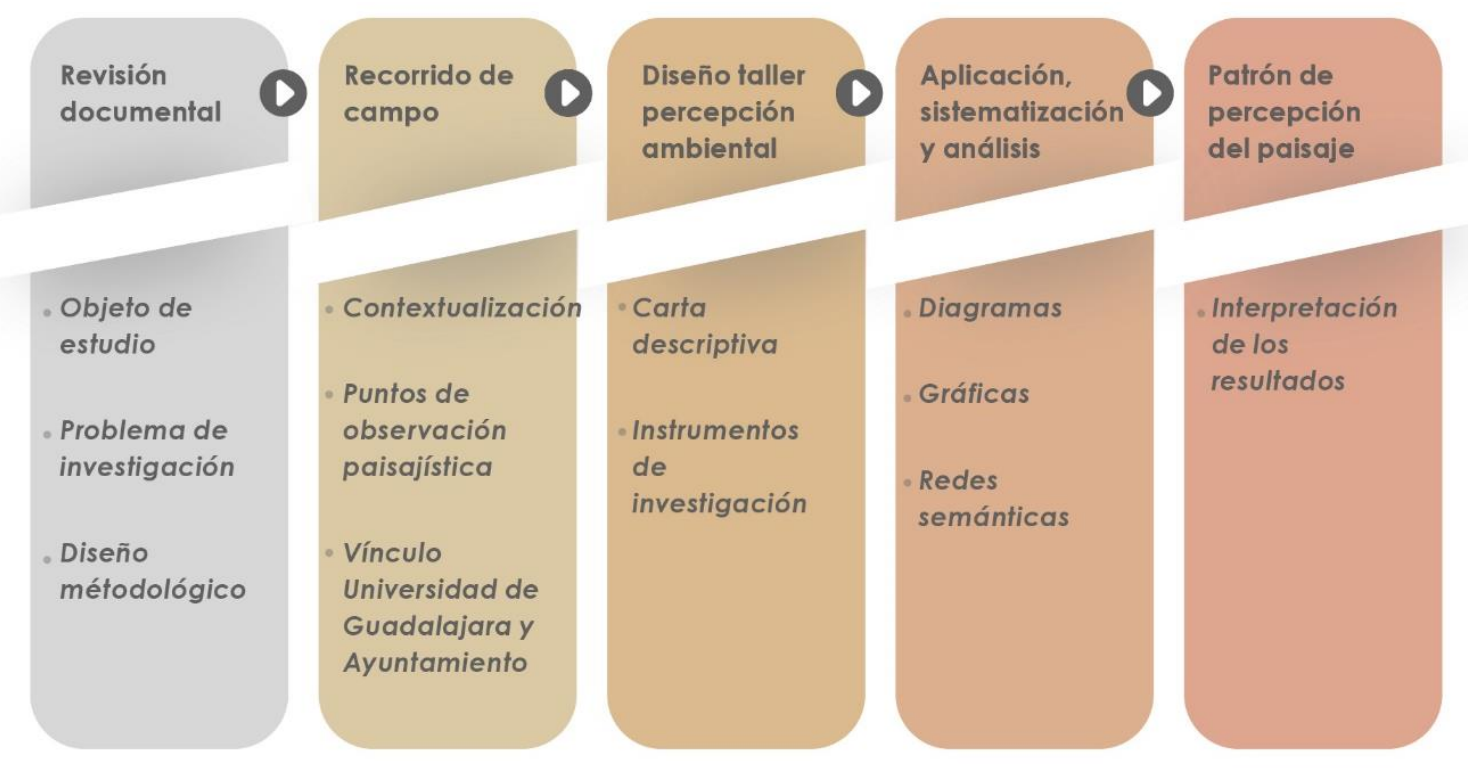

Diagrama 1 - Esquema metodológico: lectura de imágenes paisajísticas. Fuente: Elaboración propia 2021. Proyecto de Investigación. CIIEMAD, Instituto Politécnico Nacional. 
La relación teórica metodológica se traza desde dos posiciones la interpretación de los datos y la relación geografía-percepción y paisaje-percepción.

La percepción del paisaje valora la "capacidad para mostrar la realidad, invisible o no, del territorio, para hacerla entendible y apreciable por las personas que se benefician así del conocimiento y disfrute de ese bien colectivo" (Lucio \& Gutiérrez, 2011, p. 157).

De tal forma que la ciencia de la geografía ayuda a comprender el entorno por la relación que tiene la humanidad con el medio donde desarrollan múltiples procesos. Lo que en conjunto con la percepción alcanza un análisis científico más profundo del territorio y la percepción influye en el comportamiento (Durán, 2006). Además, "la geografía aborda la percepción y la imagen simbólica de los lugares, por el proceso cognitivo de los individuos en relación con su espacio" (De Souza et al., 2008, p. 107).

Desde otro enfoque, la ciencia del paisaje en relación con la percepción muestra el contexto que "se convierte en patrimonio en sí mismo, el paisaje adquiere identidad propia como bien cultural. De hecho, paisaje y patrimonio inmaterial se han convertido en [...] valores e imaginarios destacados [...] de referentes que los testimonian" (Gómez \& Agudo, 2019, p. 1218).

Desde otra perspectiva la metodología de percepción ambiental a través del dibujo, en una experiencia de investigación con niños de Colombia, de carácter cualitativo y tipo descriptivo-exploratorio, explican Suárez et al. (2020) que el dibujo lo utilizan por "recomendaciones de autores clásicos como Stand, Piaget, Arnheim, Tonucci, y Olaizola, quienes tratan la importancia de la expresión de las relaciones entre el niño y el entorno" (p. 21).

Estos autores explican que en los dibujos se observan las distintas etapas de crecimiento en los niños. Por lo tanto, "más allá de la percepción, entra en juego otro elemento en la elaboración del dibujo infantil, [...] el conocimiento previo [...] de conceptos y elementos abstractos del entorno" (Suárez et al., 2020, p. 21).

Por lo tanto, el amplio margen generacional en el Taller de percepción en Tlajomulco (4 a 87 años), permite explorar distintas imágenes del entorno. En la interpretación de esas imágenes se exploran distintos aspectos de la psicología ambiental, donde se plantea que "...los cambios a lo largo del ciclo vital tanto en los procesos como en los contenidos de la relación entre el individuo y su entorno se incluyen en un sentido más amplio las áreas de desarrollo humano" (Correa \& Ruíz, 2008, p. 2).

Así el Taller de Percepción comunitaria del Paisaje en Tlajomulco se desarrolló con el método de lectura de imágenes, el cual consistió en elaborar dibujos del paisaje de Tlajomulco. El dibujo en el argumento de Papandreou (2014, citado en Suárez et al., 2020) "es un instrumento de interpretación, [...] es una actividad humana que muestra los contextos sociales. Además, [...]el dibujo muestra los estímulos del entorno sociocultural que traza una ventana al interior del niño" (p. 22).

El método de lectura de imágenes parte de la definición de los conceptos de agricultura, ecología, inmaterialidades del paisaje, ruptura de la armonía, armonía, percepción del paisaje, comunidad, psicología ambiental y sustentabilidad (Tabla 1). Estos conceptos conforman tres categorías: 1) Paisaje de Tlajomulco, 2) Dimensiones de la sustentabilidad en Tlajomulco, y 3) Problemática ambiental (Tabla 2).

Las categorías marcan la pauta interpretativa del paisaje de Tlajomulco. Con el marco de referencia definido establecemos los siguientes trazos interpretativos: Paisaje de Tlajomulco, Paisaje de las dimensiones de la sustentabilidad en Tlajomulco, Armonía y Ruptura de la armonía en el paisaje de Tlajomulco.

Desde estas categorías se establecen tres variables para el análisis de la percepción de los habitantes de Tlajomulco: la transición rural-urbana, la sustentabilidad y la agroecología. Con ello, se interpretan las dimensiones del paisaje: agua, comunidad, suelo y flora y fauna, cuyas unidades de observación son los dibujos de los niños de 4 a 6 años, 7 a 9 años, 10 a 12 años, 13 a 17 años y los mayores de 18 años. 
Percepción del paisaje socioambiental agroecológico

Tabla 1 - Conceptos para la interpretación de la Percepción del paisaje socio ambiental en Tlajomulco

\section{CONCEPTOS}

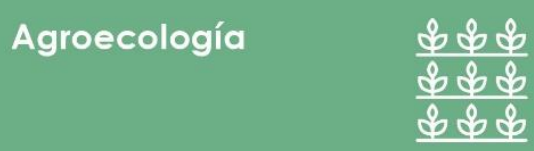

\section{Comunidad}

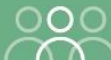

\section{Producción}

alternativa

del paisaje

\section{Dimensión \\ ambiental}

\section{Dimensión} social
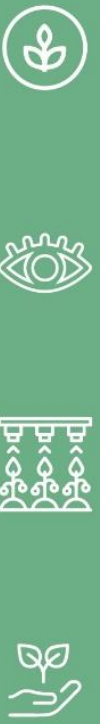

\section{Dimensión económica}

Armonía

Ruplura de

la armonía

\section{DEFINICIÓN}

"La agroecología como movimiento (e indirectamente su auge como ciencia) es una respuesta al modelo de producción que tendió, de manera global, a

homogeneizar y simplificar los agroecosistemas así como a erosionar la diversidad genética en los cultivos" (Jardón, 2018, p. 11).

"Destinatario y soporte territorial de la intervención comunitaria y de procesos y características de integralidad, recursos, participación y organización global y contexłual que nacen de la comunidad geográfica o se organizan siguiendo su estructura territorial" (Sánchez, 2020, p. 10)

Distintos tipos de agricultura que se basa en procesos de producción nałural que abona a una matriz agroecológica de interacción con recursos naturales en nichos individuales hasta generar redes que permiten establecer patrones de agrobiodiversidad en estructuras y redes funcionales propias de campesinos.

Interpretación intangible de la expresión de pensamientos, ideas y emociones que crean identidades del lugar.

Aproximación ambiental a los sistemas productivos agrícolas con elementos naturales, ecológicos y productivos útiles para los agroecosistemas.

Reconocimiento al potencial humano como agricultor rural y urbano, con aspectos que contribuyen a la dignificación del ser humano con la agricultura, alimentación y soberanía alimentaria. "El agricultor es la profesión propia del sabio, la más adecuada al sencillo y la ocupación más digna para łodo hombre libre" Cicerón (106-43 a.C.).

Aproximaciones a actividades de economía solidaria a diferentes escalas en busca de autonomía y desarrollo local.

Elementos que establecen la multifuncionalidad del paisaje, contribuyendo a la mejora ambiental, la generación de agrobiodiversidad y soberanía alimentaria.

Elementos que generan presión y problemas socio ambientales de vulnerabilidad en los sistemas alimentarios.

Fuente: Elaboración propia 2020. Proyecto de Investigación. CIIEMAD, Instituto Politécnico Nacional. 
Tabla 2 - Trazos interpretativos para el análisis por categoría del método de lectura de imágenes

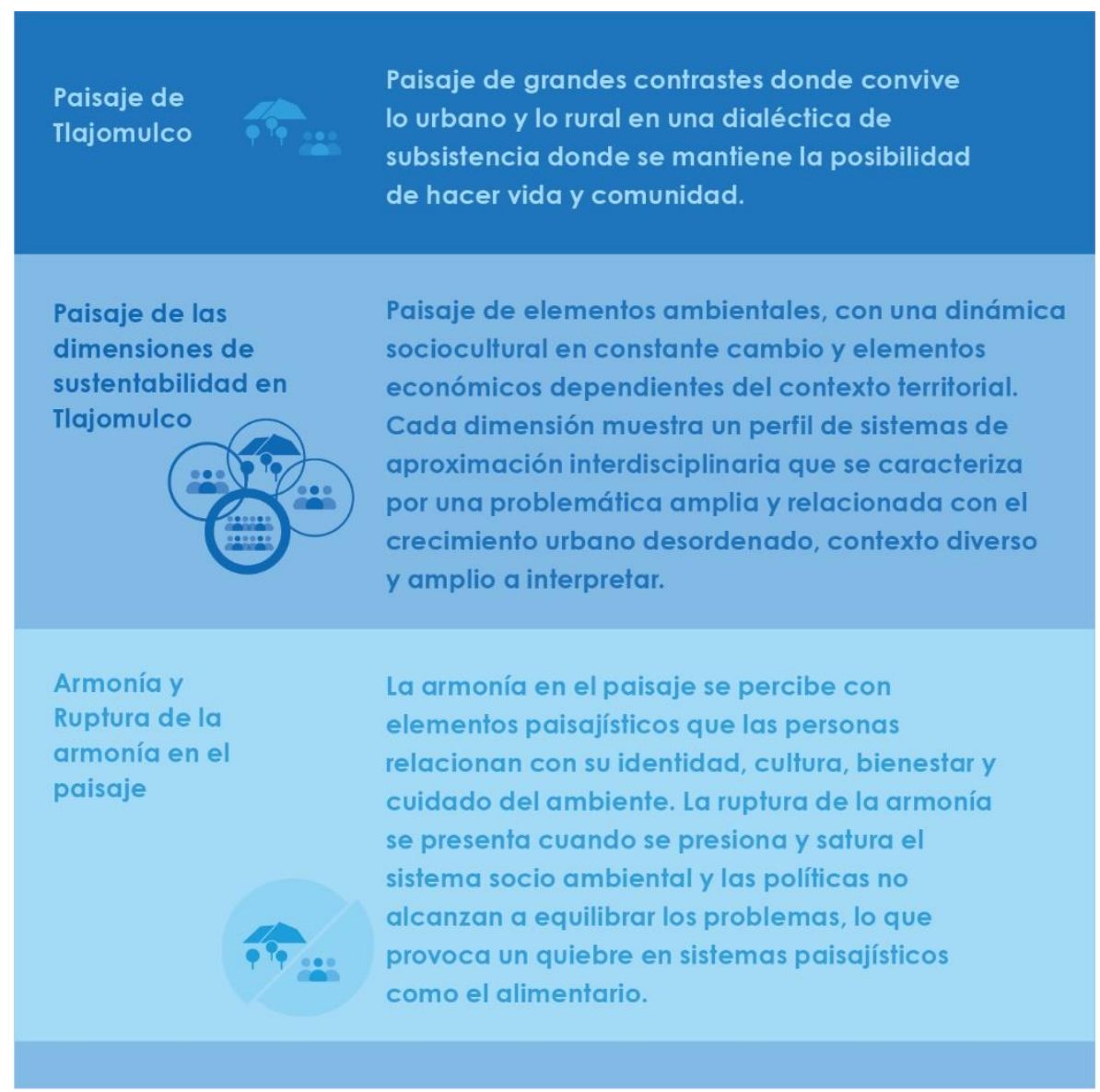

Fuente: Elaboración propia 2021. Proyecto de Investigación. CIIEMAD, Instituto Politécnico Nacional.

Cabe señalar que desde esta perspectiva se habla de una agroecología que "no se basa en recetas técnicas, sino en principios; de ahí que no se trate de una agricultura de insumos, sino de procesos" (Rosset \& Altieri, 2019, p. 24)

Los indicadores de referencia son: la armonía, la ruptura de la armonía y el paisaje agroecológico. Por lo tanto, la información se obtiene de los métodos descriptivo y constructivista con la técnica participante y la aplicación de cuatro instrumentos.

\section{Instrumentos y materiales}

Los cuatro instrumentos del método de lectura de imágenes del paisaje son: a) Obtención de imágenes del paisaje a través del dibujo; b) Recopilación de los elementos del paisaje en las imágenes; c) Análisis de los elementos percibidos del paisaje por dimensión paisajística de la sustentabilidad y la ruptura de la armonía; y Síntesis de la información para presentar los resultados (Tabla 3).

De ahí que la aplicación de los instrumentos en el Taller de Percepción comunitaria del Paisaje en Tlajomulco se diseñó con el fin de identificar los elementos paisajísticos más significativos en las imágenes con relación a la agricultura, ecología, problemática y dimensiones de la sustentabilidad para perfilar el panorama de la agroecología en Tlajomulco desde el paisaje. 
Tabla 3 - Modelo de operacionalización de variables del método de lectura de imágenes

OPERACIONALIZACIÓN DE VARIABLES DEL MÉTODO DE LECTURA DE IMÁGENES

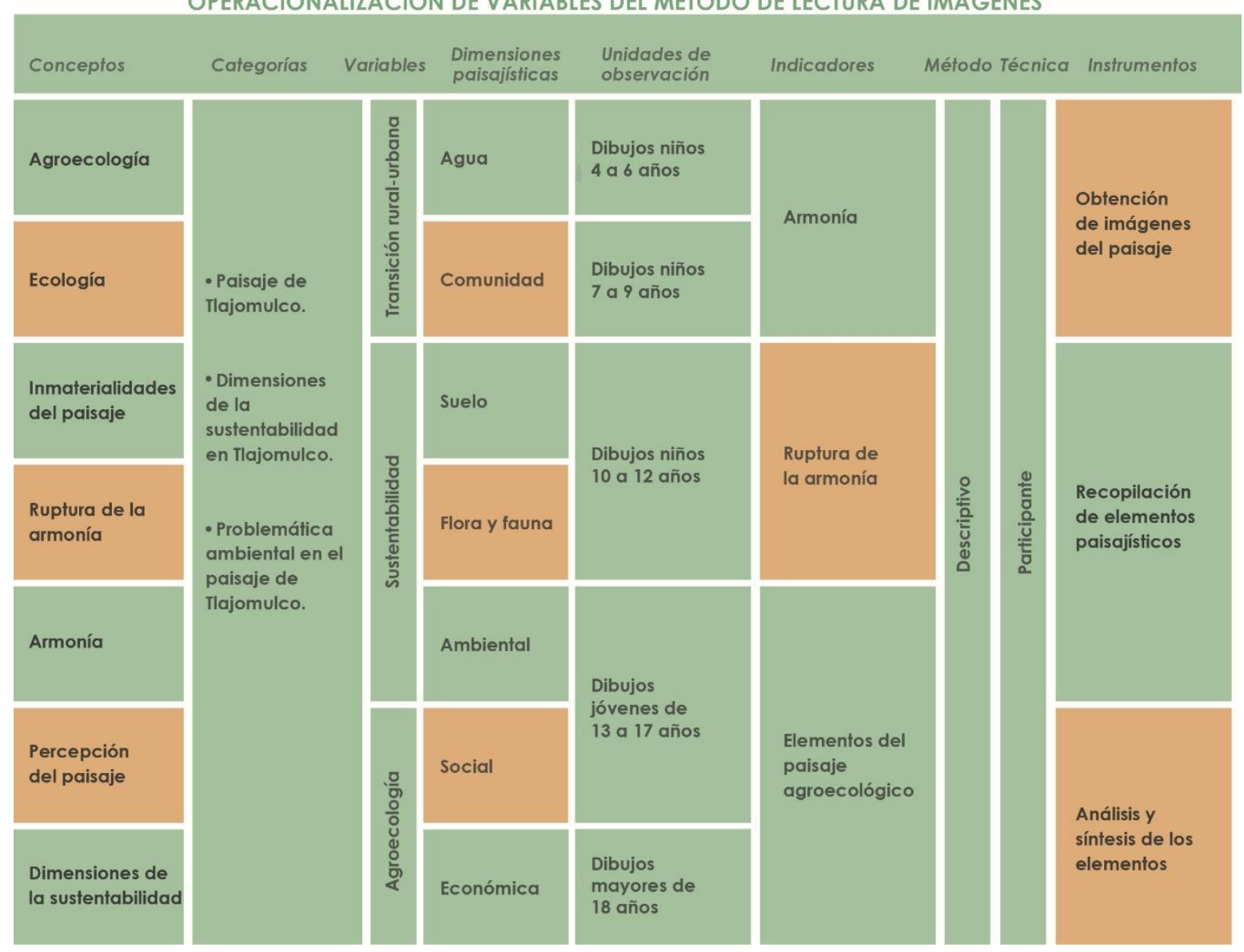

Fuente: Elaboración propia 2021. Proyecto de Investigación. CIIEMAD, Instituto Politécnico Nacional.

Para obtener las imágenes del paisaje a través del dibujo se preparó una ficha donde se colocan las imágenes diseñadas por los participantes en cada dimensión paisajística (agua, suelo, comunidad y flora y fauna). La pregunta detonadora cada vez que se elaboraba un dibujo fue ¿Cómo se perciben los elementos del paisaje de Tlajomulco? Así se exploraron el agua, la comunidad, el suelo y la flora y fauna.

En la recopilación de los elementos del paisaje, con cada dibujo se tipificaron los elementos observados por edad y dimensión paisajística y los datos obtenidos se ordenan en tabla de contingencia. Una vez identificados y cuantificados los elementos se analizaron los resultados agrupándolos por dimensión de la sustentabilidad (ambiental, social y económica) y la dimensión paisajística observada con lo que se construye una red semántica con la que se interpreta el paisaje percibido y se construye el concepto del paisaje agroecológico.

La forma connotativa de buscar el significado a las palabras lo explica Moreno (1999, citado en FraijoSing et al., 2018) como "...referencia a un objeto, de manera subjetiva, particular y contextual, tal como el significado psicológico, que puede tener una función mediadora entre el objeto y las conductas” (p. 234). Existen diferentes referencias para explicar la forma de abordar el estudio de los significados a través de las redes semánticas, ya que la riqueza de este instrumento se relaciona con procesos "de reconstrucción en la memoria, para la construcción del concepto. Cuando se elabora una red semántica, entre más palabras adquiere la red el significado de un concepto se amplía (Fraijo-Sing et al., 2018, p. 234).

En la observación de las imágenes, se encontraron las "fases de comprensión, interpretación y significación. El reto continúo es explicitar la relación con el marco teórico dado y que se admite a la técnica en general como una teoría y un método en el acto" (Rojas, 2011, p. 292). Así surge la posibilidad que el observador como actor en el paisaje revele su interacción con el entorno donde se liga la temporalidad, las transformaciones y arraigo al lugar que se establecen de forma potencial o inferida. 
Con la interpretación de la percepción se dan los primeros pasos para comprender el paisaje como una construcción humana, porque un paisaje no existe en sí mismo, sino únicamente en las mentes de quienes asocian una serie de características en la tierra como un paisaje específico (Muñoz, 2004).

En este sentido existen cuatro propiedades del paisaje que sirven de referencia: "coherencia (información inmediata + necesidad dar sentido al entorno), complejidad (información inmediata + necesidad de implicarse en el entorno), legibilidad (información potencial + necesidad de dar sentido al entorno) y misterio (información potencial + necesidad de implicarse al entorno)" (López-Contreras et al., 2019, p. 1091).

De cierta forma el espacio y su relación con el tiempo se manifiesta en procesos del medio ambiente como argumenta Wallon (1984, citado en Suárez et al., 2020) “[...] cuya espacialidad es la toma de conciencia del sujeto de su situación y de sus posibles situaciones en el espacio que le rodea, y los objetivos que en él se encuentran" (p. 23).

$\mathrm{Al}$ respecto el sistema de valores que posee un individuo lo ubica en un lugar en relación con la naturaleza, a través de las vivencias se regula la dirección del desarrollo personal puesto que produce efectos positivos emocionales de congruencia y empatía ambiental lo que se refleja en la percepción del ambiente. Al respecto, la percepción "es un proceso psicológico humano, una función del sistema psicológico en desarrollo que necesita actualizarse y que como proceso tiene un inicio y un fin, es una secuencia de momentos que se caracteriza por su enriquecimiento" (Tserej \& Febles, 2013, p. 33).

\section{Resultados}

Tlajomulco de Zúñiga es un municipio conurbado con un paisaje de superficie plana y ligeramente deformada, cerros y colinas con recursos naturales y pueblos tradicionales de importancia para la región, en una extensión de 636.93 kilómetros cuadrados y una población de 549,442 habitantes (IIEG, 2018). Tlajomulco se localiza al sur del Área Metropolitana de Guadalajara (AMG), y colinda con los municipios conurbados Zapopan, Tlaquepaque, El Salto e Ixtlahuacán de los Membrillos (Mapa 1).

El crecimiento poblacional, en Tlajomulco de Zúñiga es aproximadamente de 70 veces en veinte años, lo que se traduce en la pérdida de huertas por complejos inmobiliarios, las descargas de aguas residuales de la cabecera municipal, la mortandad de las popochas o pintitas (Astyanax aeneux) y fraccionamientos aledaños a la Laguna de Cajititlán, los deslaves de Cerro Viejo aunado al paso del macro libramiento de Guadalajara en la zona de amortiguamiento del Área Natural Protegida de Cerro Viejo-Chupinaya-Los Sabinos muestra una versión rural de la pérdida de patrimonio del AMG (PACMUBIS, 2018). 


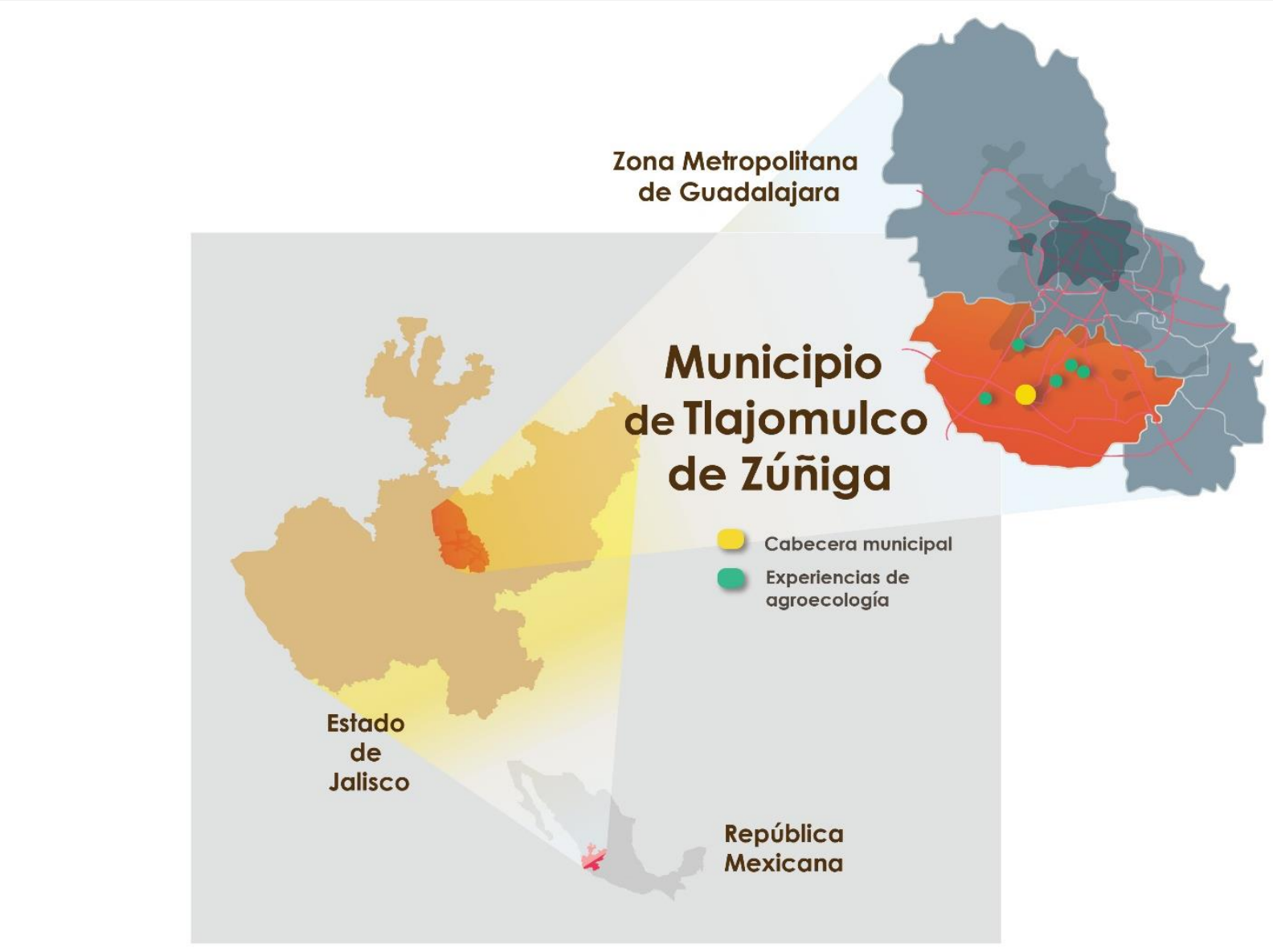

Mapa 1 - Localización de Municipio Tlajomulco de Zúñiga Jalisco, México. Fuente: Elaboración propia, 2019. Proyecto de Investigación. CIIEMAD, Instituto Politécnico Nacional

\section{Participantes en el taller "Percepciones paisajísticas en Tlajomulco de Zúñiga"}

La convocatoria para participar en el taller se realizó en las seis zonas del plan de ordenamiento ecológico de Tlajomulco 2019: 1) Concepción del Valle-Cerro del Gato; 2) Cajititlán-Cerro Viejo; 3) San Agustín-La Primavera; 4) Tlajomulco-Latillas; 5) Santa Cruz-Totoltepec; y 6) El Zapote-El aeropuerto (Mapa 2).

La división territorial presenta el criterio de que cada zona incorpore un recurso natural de relevancia local, un componente agrícola y un componente urbano. Bajo esta lógica las personas tienen a la mano elementos que ayudan a integrar una dinámica territorial para establecer políticas públicas más equitativas. No obstante, los recursos naturales más reconocidos son la Laguna de Cajititlán, Cerro Viejo y el Bosque La Primavera y las actividades agrícolas son las que prevalecen en el municipio, aunque el crecimiento urbano es inminente (CIESAS, 2019).

El taller de percepciones paisajísticas se llevó a cabo en el CAT (Centro Administrativo de Tlajomulco), ubicado en la cabecera municipal, con una participación de 152 personas. Esta participación se logró a través de la convocatoria del gobierno municipal y la logística de transporte con autobuses que salieron de cada zona del municipio.

La invitación se hizo a grupos ya organizados del programa municipal de agricultura urbana; estudiantes de los diplomados de turismo sustentable y promotores de comunidades sustentables que el municipio desarrollo en conjunto con la Universidad de Guadalajara; el programa de escuelas sustentablesguardianes de la tierra y el programa de reforestación que tenía participación de personas de todo el municipio. Además del grupo de Scouts de Lomas del Sur. Esta red de colaboración ambiental con grupos de trabajo se estableció como una estrategia multisectorial por el municipio para establecer la agenda ambiental y aumentar las capacidades ambientales de la población. 


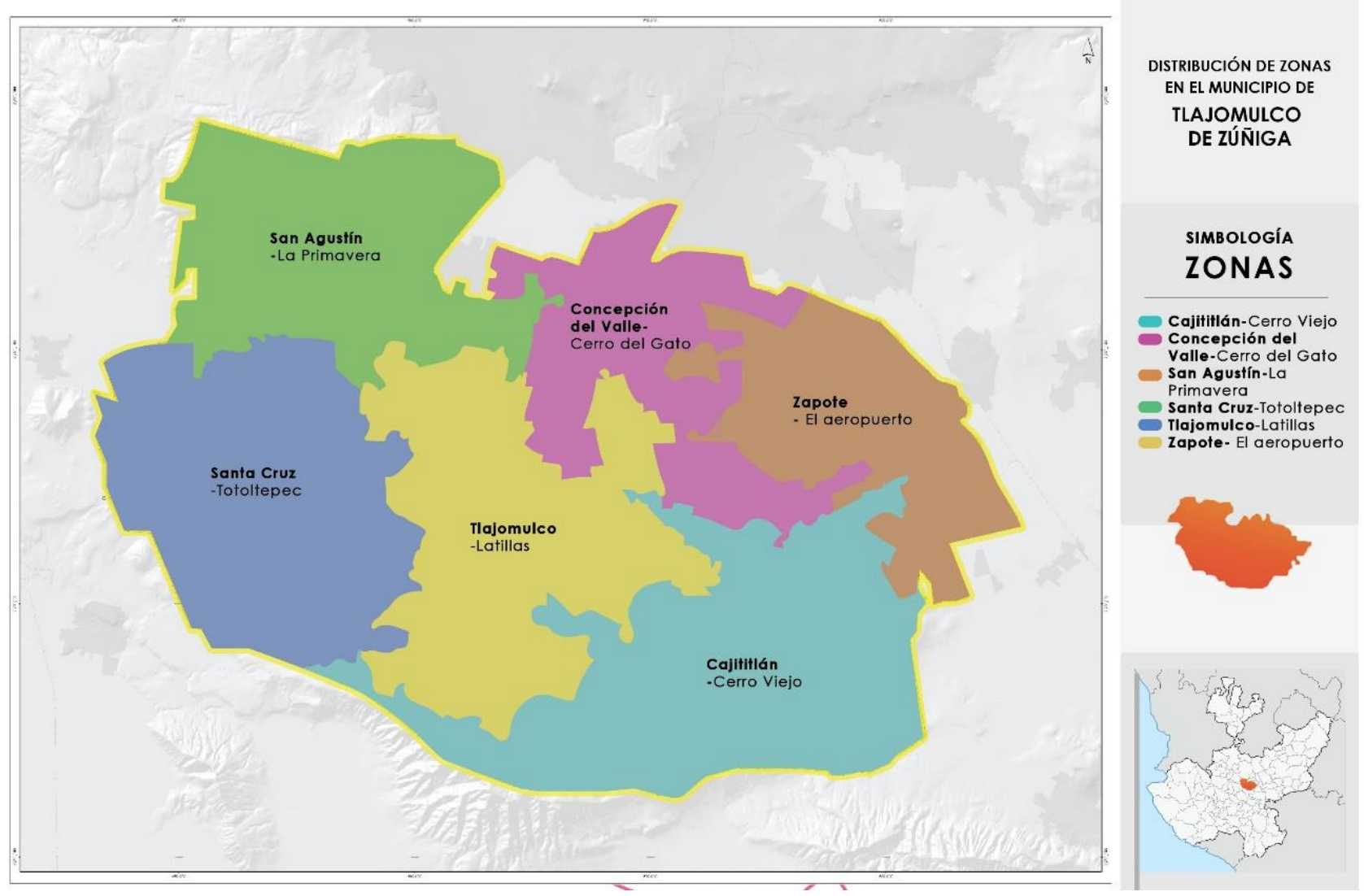

Mapa 2 - Zonas del municipio de Tlajomulco, POEL 2019. $\square$ San Agustín-La Primavera, C Concepción del Valle-Cerro del Gato, El Zapote-aeropuerto, $\square$ Cajititlán-Cerro Viejo, — Tlajomulco-Latillas, — Santa Cruz de las Flores-Totoltepec. Fuente: Jorge Alberto Cruz Barbosa. CIESAS (2019) Laboratorio de geografía.

Los participantes del taller (Tabla 4) y (Fig.1) fueron: 46 de Concepción del Valle-Cerro del Gato; 30 de Cajititlán-Cerro Viejo; 29 de San Agustín-La Primavera; 15 de Tlajomulco-Latillas; 13 de Santa Cruz de las Flores-Totoltepec; y 12 de El Zapote-El aeropuerto. Cabe destacar que la mayoría de los participantes vinieron de la zona Concepción del Valle-Cerro del Gato con el crecimiento demográfico más intenso del municipio y los proyectos de agricultura urbana emblemáticos de la zona. En segundo lugar, Cajititlán-Cerro Viejo donde se encuentran los pueblos tradicionales y las experiencias de agroecología por parte de los comuneros del lugar. 
Percepción del paisaje socioambiental agroecológico

Tabla 4 - Participantes al taller de percepción de Tlajomulco de Zúñiga

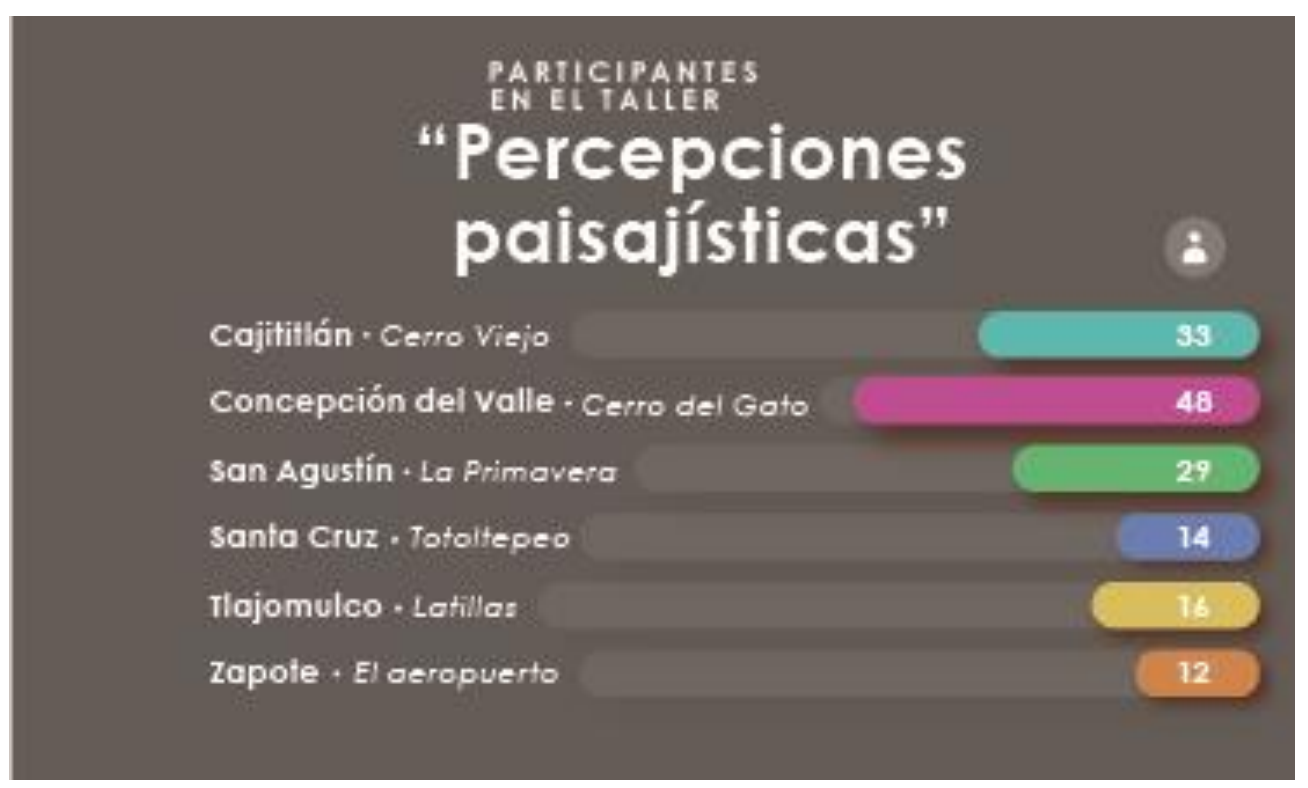

Fuente: Elaboración propia 2021. Proyecto de Investigación. CIIEMAD, Instituto Politécnico Nacional

En proporción la participación tuvo una representación de todas las zonas del municipio (Fig. 1).

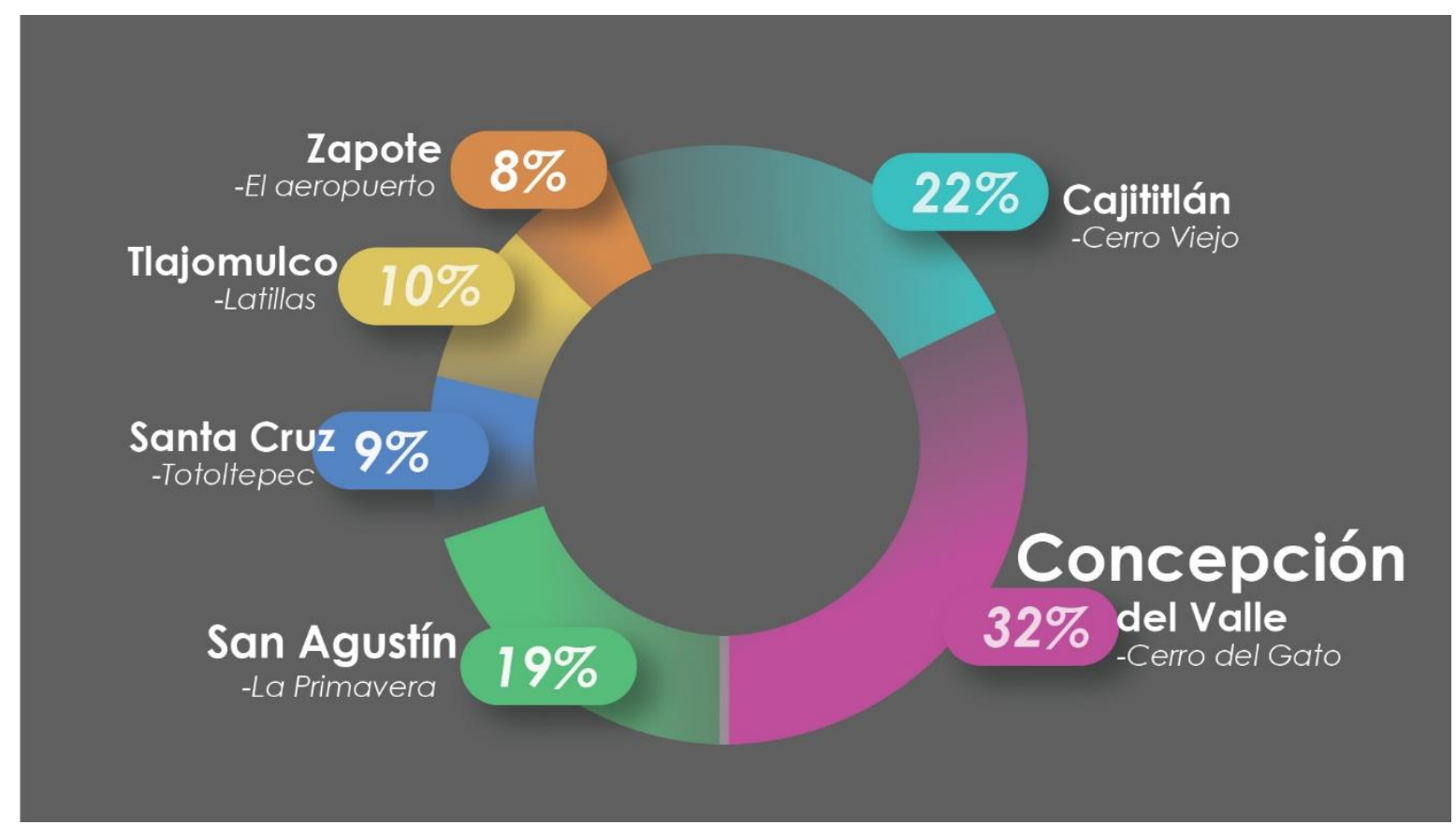

Figura 1 - Promedio de participantes por zona de Tlajomulco. Elaboración propia 2021. Proyecto de Investigación. CIIEMAD, Instituto Politécnico Nacional.

En relación con la participación de mujeres y hombres se tuvo la presencia de 93 mujeres y 59 hombres. Las edades de los participantes del taller se distinguieron por color y asistieron: de 4 a 6 años verde, 10 niños; de 7 a 9 años café, 24 niños; 10 a 12 años naranja, 21 niños; 13 a 17 años azul, 14 jóvenes adolescentes y mayores de 18 años morado, 78 participantes (Fig. 2). 


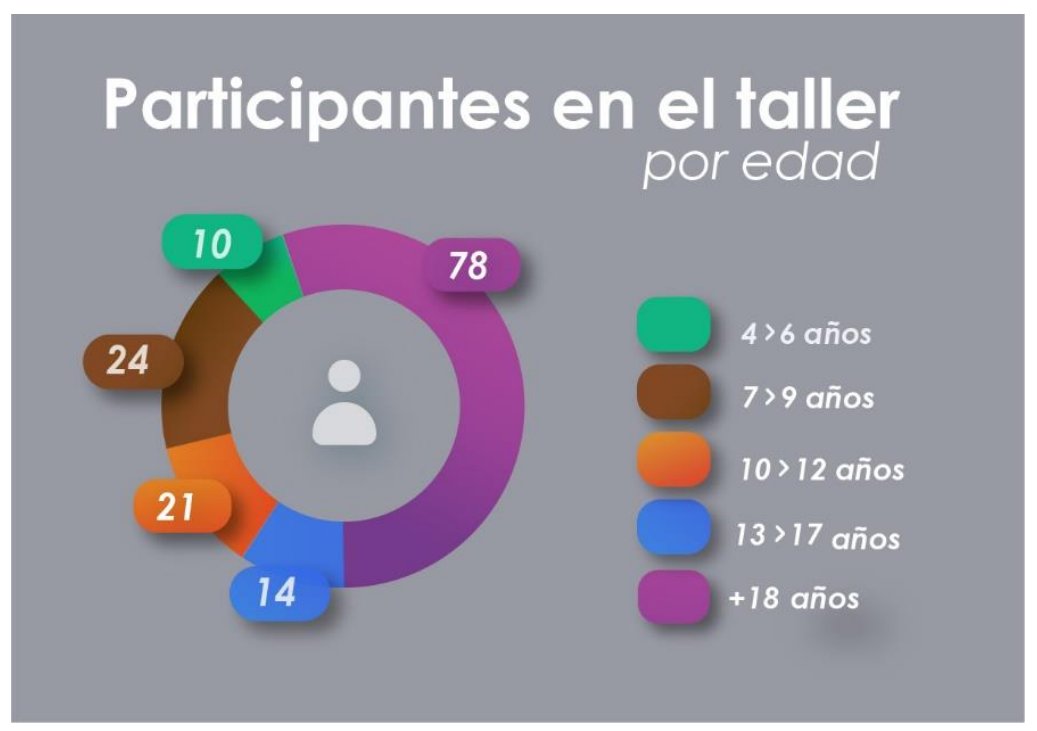

Figura 2 - Participantes por edad en el taller. Fuente: Elaboración propia 2021. Proyecto de Investigación. CIIEMAD, Instituto Politécnico Nacional

\section{a) Obtención de imágenes del paisaje a través del dibujo}

En el taller se elaboraron 557 dibujos, con los datos se construyó una red semántica por cada dimensión paisajística y se calculó la proporción de elementos que observaron los participantes por dimensión de la sustentabilidad y se relacionó con la armonía y la ruptura de la armonía en cada grupo de edad.

Los elementos paisajísticos que se encuentran en la ficha de obtención de dibujos de Tlajomulco, (Fig. 3) muestran los cambios que ha tenido el municipio con la periurbanización y la búsqueda de la permanencia de los recursos naturales, culturales y agrícolas.

Un ejemplo del tratamiento de los dibujos que se obtuvieron se observa en la Fig. 3 es el siguiente:

Agua: 10-12/13 (Identificación del dibujo), se enlistan diez elementos de los cuales siete tienen relación con la ruptura de la armonía. Ahí se señala que el entorno está deteriorado y los niños se dibujan como observadores. En los dibujos del grupo de edad de 10 a 12 años se advirtió una proporción equitativa en los elementos por dimensión de la sustentabilidad y paisajística. Además de percibir ampliamente la ruptura de la armonía.

Comunidad: 4-6/1 se enlistan 6 elementos relacionados con la naturaleza, en los dibujos del grupo de edad de 4 a 6 años sobresalen los elementos naturales; el aspecto social y la ruptura de la armonía tienen menor relevancia.

Suelo: 13-17/6 se enlistan 8 elementos de los cuales se conjugan en la transición rural urbana. Destaca el reconocimiento del paisaje y la interacción social, lo que se traduce en mayor claridad de la problemática local. Los jóvenes de 13 a 17 años hacen referencia a los fraccionamientos como parte del suelo y la producción de vegetales limpios en parcelas, como si no hubiera una división con el paisaje rural. En este sentido integran las dimensiones de la sustentabilidad con los elementos del paisaje y la ruptura de la armonía de forma puntual.

Flora y fauna: Mayor 18/31 se enlistan 11 elementos, destaca que se caracteriza de forma general a los animales y el paisaje se ve inmerso en la ciudad, incluyen algunos elementos rurales como la milpa. Los mayores de 18 años enmarcan espacialmente Cerro Viejo y los afluentes de agua junto con las aves acuáticas y la problemática la relacionan con el ámbito social. 


\section{INSTITUTO POLITÉCNICO NACIONAL CENTRO INTERDISCIPLINARIO DE INVESTIGACIONES Y ESTUDIOS SOBRE MEDIO AMBIENTE Y DESARROLLO Doctorado en Ciencias en Conservación Patrimonial Paisajistico. Red IPN}

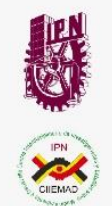

Tesis: "Conservación Del Patrimonio Agroecológico Armónico, En Tlajomulco De Zúñiga Jalisco, México: "Concepción Del Valle - Cerro El Gato" Y "Cajititlán - Cerro Viejo"

Objetivo: "Estudiar la relación socioambiental del Paisaje Agroecológico Armónico en Tlajomulco de Zúñiga en su conformación con la factibilidad de manejo para su conservación"

Edad: Agua

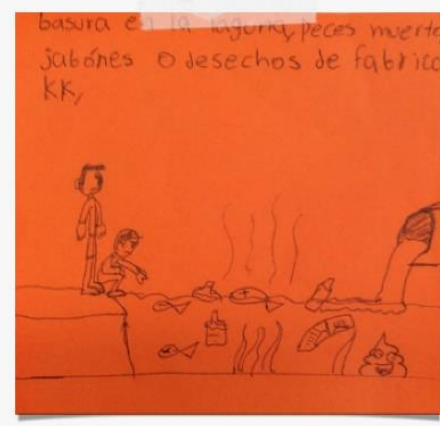

Suelo

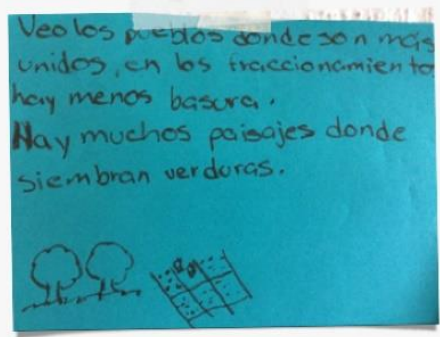

Sexo:

Comunidad

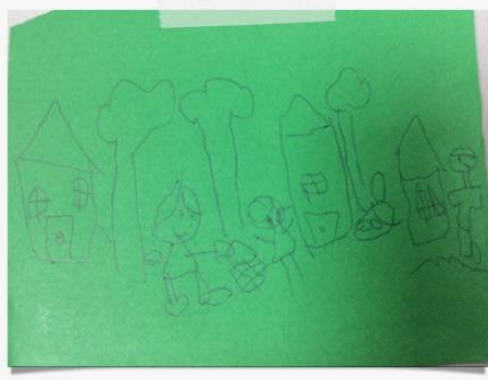

Flora y fauna

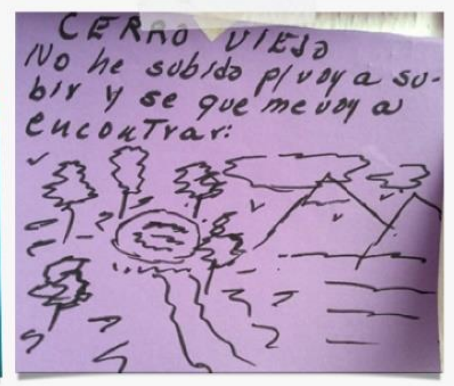

A partir de explorar nuestro municipio con el recorrido narrativo de nuestra compañera Ana, imagina que vemos en Tlajomulco a través del agua, comunidad, suelo y flora y fauna y dibújalo.

Figura 3 - Ficha de obtención de imágenes, con dibujos de distintas edades. Elaboración propia 2019. Proyecto de Investigación. CIIEMAD, Instituto Politécnico Nacional

Lo que se observa al enlistar los elementos paisajísticos es que la forma de percibir el entorno en los niños y jóvenes varía de acuerdo con su edad, ya que "mientras más pequeños ven la naturaleza, como una figura estática. Estos símbolos no presentan un orden espacial y su relación lo atribuyen al significado emocional" (Cuervo López et al., 2015, p. 1742).

\section{b) Recopilación de los elementos del paisaje en las imágenes}

Los 557 dibujos se trataron como unidades de observación (Tabla 5). Los niños de 4 a 6 años elaboraron 33; de 7 a 9 años 97; de 10 a 12 años 127; de 13 a 17 años 59; y mayores de 18 años 239. 
En la interpretación se cuidó de no perder la riqueza de lo observado por el siguiente motivo: la figura del "elemento del paisaje" permite proteger enclaves de gran interés ambiental en áreas agrarias y es importante aumentar su conocimiento entre los agricultores (Rodríguez, 2020) y habitantes.

Tabla 5 - Unidades de observación sistematizadas por edad de participantes

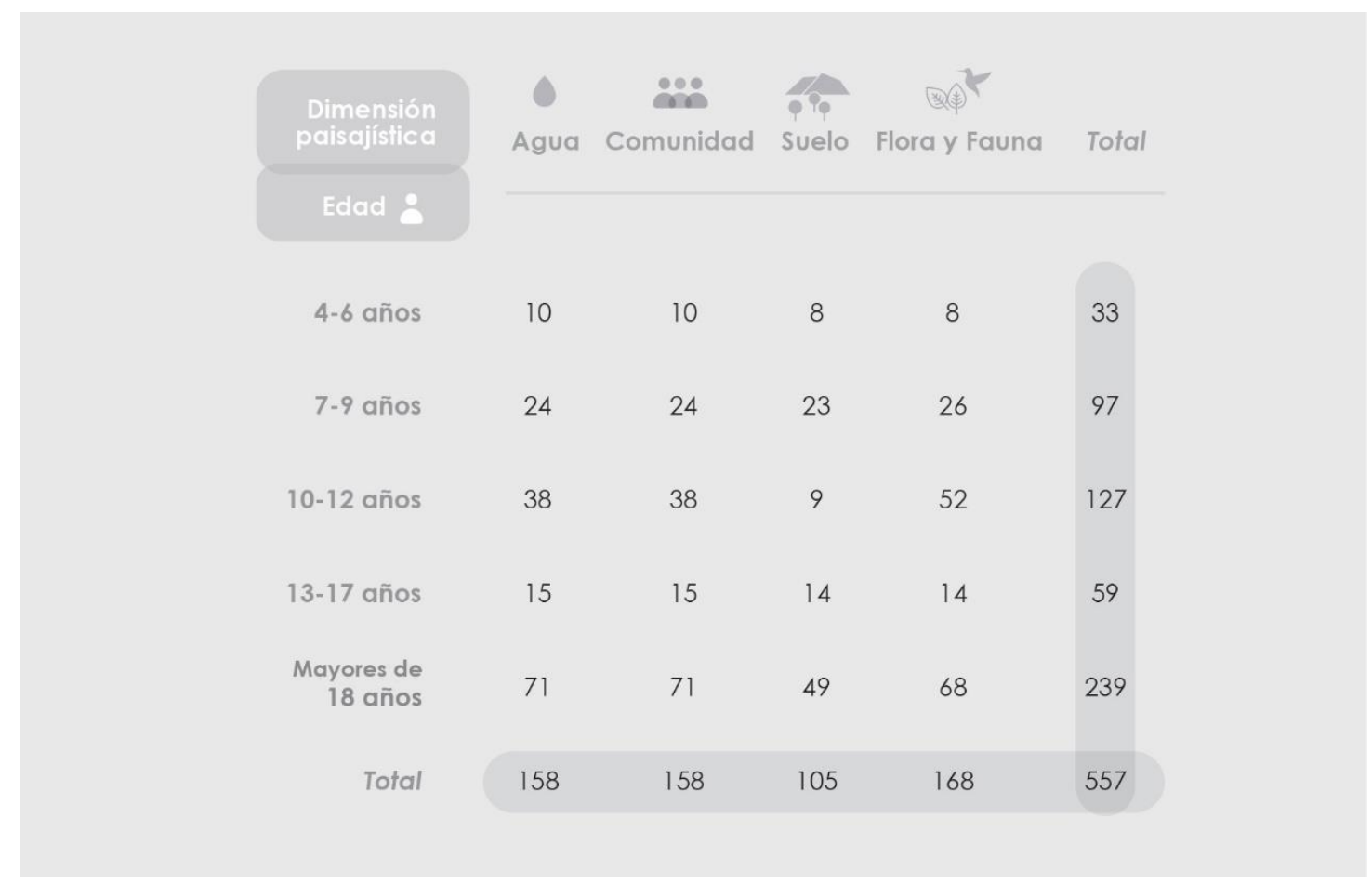

Fuente: Elaboración propia 2021. Proyecto de Investigación. CIIEMAD, Instituto Politécnico Nacional.

La referencia para interpretar dibujos de niños desde 4 años se da "con la contextualización de la realidad de un territorio que ayuda a transitar hacia al paisaje a través de la acción del sujeto. Los niños como seres únicos, singulares, con capacidad de conocer, sentir, opinar, plantean problemas para buscar soluciones" (Suárez et al., 2020, p. 23). Lo que aporta herramientas para ligar elementos de la problemática ambiental con la agroecología.

Al mismo tiempo se destacan los elementos que desarticulan a las comunidades agrarias, por lo que la prioridad son los elementos que ayudan a reestablecer sistemas alimentarios desde múltiples perspectivas. Es decir, elementos de rearticulación de un "paisaje cultural para su activación y detener la tendencia a convertirse en un vestigio" (Cabana, 2008, p. 33).

\section{c) Análisis y síntesis de los elementos percibidos del paisaje por dimensión con relación a la sustentabilidad y la ruptura de la armonía}

El análisis de las imágenes refleja cómo los habitantes perciben la pérdida de los recursos naturales, rurales y agrícolas, señalando a los sistemas productivos que persisten como alternativa de vida. Además, la agricultura convencional que contamina y los asentamientos urbanos que crean y recrean formas de vivir vulnerables. La consecuencia es un desarrollo impuesto cuyo proyecto privilegia los intereses inmobiliarios y económicos que no priorizan la planificación, ordenación y gestión de los espacios naturales y rurales.

La percepción e interpretación de las dimensiones como el agua, comunidad, suelo y, flora y fauna dan un significado al paisaje de Tlajomulco, pues son referencias en uso para observar la manera en que los habitantes por grupo de edad se identifican con su entorno. En particular se integra la apreciación de la estructura social para determinar cómo se manifiestan en ella las pautas sociales y culturales. Por lo tanto, "el sujeto es interactivo [...] al contribuir activamente en conexión con otros a crear suministros, alterar 
significados y modificar su entorno. [...] Así el Desarrollo Humano se alcanza al potenciar los recursos existentes y crear suministros necesarios para la resiliencia" (Sánchez, 2020, p. 19).

De esta manera las redes semánticas permiten generar un constructo conceptual de las dimensiones paisajísticas percibidas, como sigue:

- El paisaje del agua, elemento articulador del territorio en Tlajomulco evoca a la Laguna de Cajititlán y sus fuentes de agua como Cerro Viejo y sus ríos. El agua refleja la vida y tradición del lugar, es indispensable para la agricultura, pesca, turismo y actividades como la peregrinación de los reyes magos que dan identidad y reconocimiento cultural. Fuente de vida que sufren la ruptura de la armonía por el crecimiento urbano y los sistemas productivos convencionales.

- El paisaje de la comunidad refleja conexión con la naturaleza por persistencia o nostalgia de sus habitantes, transita de pueblos tradicionales a espacios urbanos en contrastes sociales. Con un crecimiento demográfico exponencial busca infraestructura y organización para poder vivir mejor. La ruptura de la armonía se da con la ruptura del tejido social por cuestiones de miedo, inseguridad y violencia.

- El paisaje del suelo de Tlajomulco es el del niño con sus manos llenas de tierra, donde se reconoce al campesino quien establece sistemas productivos como la milpa, la parcela, los viveros urbanos, el huerto mandala, las farmacias vivientes, los cuales se establecen a base de la fertilidad de la tierra con el uso de compostas, tierra de excremento, buscando nutrir la tierra. Reconocen la presencia de proyectos agroecológicos como el Maíz Azul, la Casa del Maíz y el Mercado Orgánico donde se fomenta la cultura y la capacitación para mejorar la alimentación. El paisaje del suelo es una transición rural urbana de potencial agroecológico. La ruptura de la armonía se da por la contaminación con químicos, basura, la disminución de las tierras de siembra por la construcción de fraccionamientos con casas y departamentos inhumanos, el aumento de enfermedades y accidentes de distintos tipos.

- El paisaje de flora y fauna de Tlajomulco donde se transita por la biodiversidad de la Laguna de Cajititlán, La Primavera y Cerro Viejo como parte de los recursos naturales del lugar, incorpora relictos naturales urbanos como los parques, jardines, la milpa, el Maíz Azul y recursos como el aire, el agua, la tierra que proporcionan la condiciones para garantizar la alimentación, el disfrute, la permanencia de la naturaleza y el planeta como base de la tranquilidad, relajación, alegría que se traduce en vida. El ámbito social tiene potencial y el maíz es la planta más mencionada en la producción del municipio. La ruptura de la armonía aparece con drogas entre las plantas del bosque y siembras, la contaminación, las quemas, erosión, la deforestación como causante de deslaves que ya han generado desastres naturales.

\section{Distribución de los elementos paisajísticos en las dimensiones de la sustentabilidad}

Se encuentra una relación de diferentes proporciones en cada grupo de edad con las dimensiones de la sustentabilidad, que se refleja en la distribución de los elementos percibidos que se señala en la figura 4. En primer lugar, destaca la dimensión ambiental hasta llegar a los jóvenes de 13 años en adelante donde se observa que tiende a tener una misma proporción con la dimensión social. La dimensión económica se mantiene aparentemente en la misma proporción por grupo de edad ya que prevalece la actividad primaria en la zona y no se percibe otra más que en ese sentido. Ahora, la ruptura de la armonía presenta la complejidad del contexto en Tlajomulco, así como el nivel de conocimiento e involucramiento que se puede alcanzar conforme la edad. 


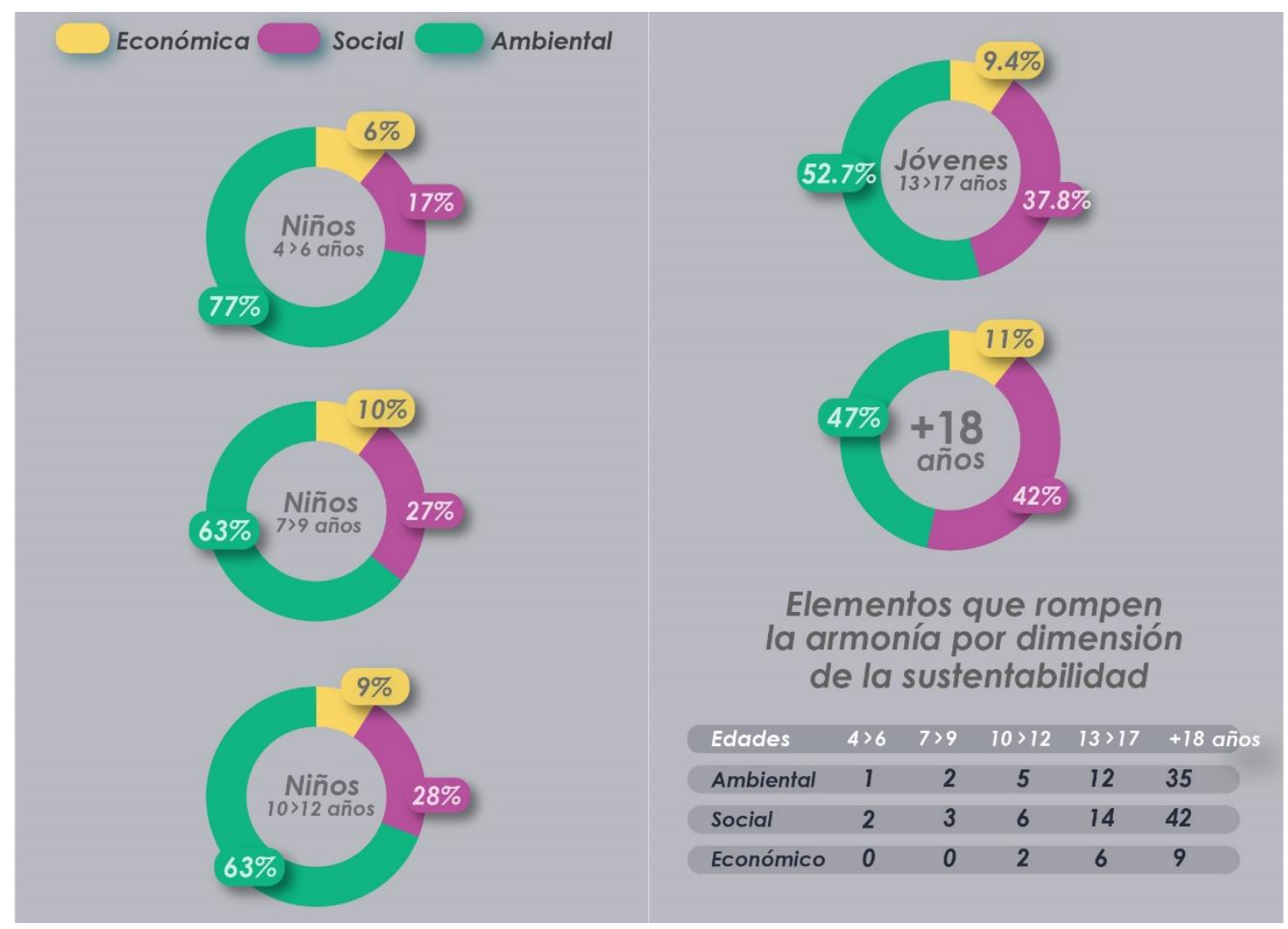

Figura 4 - Gráficas de distribución de los elementos paisajísticos por grupo de edad y su ruptura de la armonía. Elaboración propia, 2021. Proyecto de Investigación. CIIEMAD, Instituto Politécnico Nacional.

Es a través de las dimensiones de la sustentabilidad donde se destaca el potencial de desarrollo humano, ya que cada grupo de edad mostró cómo se identifican en el entorno por lo que se plantean estrategias de acción donde se aprovechan los potenciales de desarrollo de cada grupo de edad como en el paisaje agroecológico. Es decir, la percepción del paisaje agroecológico conlleva a la reflexión para la mejora del ambiente y la alimentación promoviendo el desarrollo humano como acción estratégica donde confluyen elementos resilientes para la mejora del entorno.

De esta manera el paisaje agroecológico integra espacios de agricultura alternativa, buena alimentación, proyectos de agricultura urbana y la cultura de los pueblos tradicionales de Tlajomulco. La referencia son los sistemas alimentarios percibidos. Al respecto se plantea el desarrollo humano del paisaje socioambiental como sigue:

- En la población infantil se contempla un involucramiento y compromiso ambiental que busca la conservación del paisaje. Es en este grupo de edad donde se deben facilitar los procesos y dar las herramientas para que se involucren en el cuidado de su entorno, ya que no se puede perder el interés que muestran en los elementos naturales del paisaje.

- En los jóvenes la percepción socioambiental se equilibra al integrar proporcionalmente la problemática ambiental que rompe con la armonía del paisaje. La comprensión, involucramiento y compromiso ambiental con el entorno es activo e innovador, potencial que se debe amplificar en la búsqueda de mejora del tejido social, el desarrollo humano y la conservación de los recursos naturales y culturales. La clave es permitir la acción de estos grupos en pro de su entorno en la mejora de las condiciones sociales de forma perceptible.

- En los adultos la visión del entorno y la problemática ambiental que los vulnera se enfatiza en la dimensión socio ambiental, la percepción nos muestra que las soluciones a la problemática se enfatizan en la dimensión social en distintos niveles de intervención. Se debe apostar por estrategias de generación de conciencia, involucramiento y participación. Este grupo es el más 
numeroso y denota la urgencia de involucrarse con un alto nivel de compromiso en las acciones proambientales.

\section{Conclusiones}

La percepción muestra los significados que los habitantes dan a su paisaje, el cuidado de los recursos naturales, la valoración de lo rural para la habitabilidad y la mejora de las condiciones de vida urbana como prioridad. Así, al ser el paisaje un elemento dinámico las estrategias de conservación tienen que acompañarse de acciones integradoras y resilientes como la agroecología. Se trata de generar alternativas multifuncionales que den respuesta a distintas problemáticas, de esta forma confluyen intereses y acciones de los involucrados.

El conocimiento del entorno por los habitantes nos indica la importancia de involucrar a las personas en la valoración del paisaje y su reconocimiento para definir espacios de interacción y desarrollo humano que generen infraestructura y actividades en busca de la transición hacia mejores condiciones de vida. Es decir, se deben procurar espacios de potencialización del desarrollo como el del paisaje agroecológico.

Existe un potencial inherente a la percepción del paisaje con el reconocimiento de los elementos a conservar y la influencia de las personas para lograr la generación de un patrimonio cultural e histórico que muestre una identidad del lugar para su permanencia.

Es evidente, y por lo mismo urgente, la necesidad de generar políticas públicas que garanticen los recursos naturales y agroecológicos en ámbitos rurales y urbanos que propicien servicios ambientales, que busquen mejorar las condiciones de vida como las de acceso a alimentos, seguridad, participación, conectividad, diversificación de la dieta familiar y de la economía doméstica.

Por último, los esfuerzos que otorgan identidad y cultura a los pobladores del lugar que habitan como los de percepción paisajística permiten su permanencia a través de la búsqueda de bienestar y calidad de vida.

\section{Declaración de disponibilidad de datos}

El conjunto de datos que respalda los resultados de este artículo está disponible en SciELO DATA y se puede acceder a él en https://doi.org/10.48331/scielodata.R210VX.

\section{Bibliografía}

Álvarez-Farizo, B., \& Figueiredo, F. (2008). Modelos de clase latente en la evalución de características del paisaje. Ager. Revista de Estudios sobre despoblación y desarrollo rural, (7), 58-76. Recuperado en 6 de enero de 2021 de http://www.redalyc.org/articulo.oa?id=29611863003

Aponte-García, G., Escobar-Ocampo, L. M., \& Molina-Saldarriaga, C. A. (2018). Exploración de metodologías para la valoración del paisaje. Aproximación al diseño de una metodología propia. Revista Bitácora Urbano Territorial, 28(1), 4560. Recuperado en 10 de diciembre de 2020 de http://www.redalyc.org/articulo.oa?id=74810406

Cabana, A. (2008). Lo que queda de las agras. La evolución del paisaje agrario en Galicia: A Terra Chá (1954-1968). Revista de estudios sobre despoblación y desarrollo rural (7), 33-56. Recuperado en 7 de enero de 2021 de https://www.researchgate.net/publication/277119463_Lo_que_queda_de_las_agras_La_evolucion_del_paisaje_agrario_en_ Galicia_A_Terra_Cha_1954-1968

Centro Interdisciplinario de Estudios Superiores en Antropología Social - CIESAS. (2019). Programa de Ordenamiento Ecológico Local (POEL) de Tlajomulco de Züñiga. Guadalajara: CIESAS. Recuperado en 12 de diciembre de 2020 de https://www.tlajomulco.gob.mx/noticias/programa-de-ordenamiento-ecologico-local

Correa, N., \& Ruíz, C. (2008). Psicología ambiental evolutiva: construyendo un punto de encuentro. Medio ambiente y comportamiento humano, 9 (1y2), 1-11. Recuperado en 11 de enero de 2021 de https://mach.webs.ull.es/PDFS/Vol9_1y2/Vol9_1y2_a.pdf 


\section{Percepción del paisaje socioambiental agroecológico}

Cuervo-López, L., García-Gómez, J., \& García Ferrandis, I. (2015, 5-7 de octubre). Cambio de percepción de los niños de preescolar sobre su ambiente, mediante una intervención educativa con enfoque local. Memorias del VIII encuentro nacional de experiencias en enseñanza de la biología y educación ambiental. III Congreso nacional de investigación en enseñanza de la biología, 1731-1746. https://doi.org/10.17227/20271034.vol.0num.0bio-grafia1731.1746

Cruz, J., Johannie, L., \& Soler C. C. (2018). San Andrés: cambios en la tierra y transformación en el paisaje. Cuadernos de Geografía: Revista Colombiana de Geografía, 27(2), 372-388. https://doi.org/10.15446/rcdg.v27n2.65356

De Souza, B. F., Da Silva, C. A., \& Schirley, F. N. (2008). A geografia humanística e suas relações com o ecoturismo. Revista Universitaria de Geografía, 17, 105-124. Recuperado en 8 de enero de 2021 de http://www.redalyc.org/articulo.oa?id=383239098005

Dos Santos, P. P. (2005). A análise de indicadores da qualidade visual como etapa da caracterização de paisagens turísticas: uma aplicação no distrito-sede de Porto Belo-SC. Turismo - Visão e Ação, 7(3), 417-426. Recuperado en 15 de enero de 2021 de https://www.redalyc.org/comocitar.oa?id=261056112002

Durán, V. D. G. (2006). Geografía y Percepción. Reflexiones en torno a la Enseñanza de la Geografía en la Educación Secundaria. Reflexiones, 85(1-2), 305-316. Recuperado en 16 de enero de 2021 de http://www.redalyc.org/articulo.oa?id=72920817020

Fraijo-Sing, B. S., Barrera-Hernández, L. F., Tapia-Fonllem, C. O., \& Ortiz-Valdez, A. (2018). Exploración del concepto naturaleza a partir de redes semánticas naturales en estudiantes de educación básica. Diversitas: Perspectivas en Psicología, 14(2), 233-242. https://doi.org/10.15332/s1794-9998.2018.0002.03

Gómez, A. A., \& Agudo, T. J. (2019). Paisaje e imaginarios en la percepción del turista en Andalucía PASOS. Revista de Turismo y Patrimonio Cultural, 17(6). Recuperado en 14 de enero de 2021 de https://www.redalyc.org/articulo.oa?id=88165960009

Instituto de Información Estadística y Geografía - IIEG (2018). Diagnostico Municipal Tlajomulco de Zúñiga. 1-33. Recuperado en 15de enero de 2021 de https://iieg.gob.mx/contenido/Municipios/TlajomulcodeZuniga.pdf

Lina, M. P. (2012). Metodología de la Investigación. Interdisciplinariedad del Saber Socioambiental. 13-198. Plaza y Valdes, CIIEMAD, Instituto Polítecnico Nacional.

López-Contreras, C., Chávez-Costa, A., Barrasa García, S., \& Alanís-Rodríguez, E. (2019). Bases conceptuales y métodos para la evaluación visual de Paisaje. AGROCIENCIA, 53(7), 1085-1105. Recuperado en 13 de enero de 2021 de https://dialnet.unirioja.es/servlet/articulo?codigo=7147049

Lucio, D. I. A., \& Gutiérrez C., J. J. (2011). La ciencia del paisaje, un criterio de intervención y ordenación de las Ciudades. Una propuesta de actuación sobre la vialidad solidaridad las Torres, ciudad de Toluca México. Quivera, 13(1), 156-166. Recuperado en 19 de diciembre de 2020 de http://www.redalyc.org/articulo.oa?id=40118420009

Muñoz, P. A. (2004). La evaluación del paisaje: una herramienta de gestión ambiental. Rev. Chilena Historia Natural. 77, 139-156. Recuperado en 26 de diciembre de 2020 de https://scielo.conicyt.cl/scielo.php?script=sci_arttext\&pid=S0716078X2004000100011

PACMUBIS. (2018). Plan de Acción Climática Municipal Basado en el Bienestar y la Sustentabilidad. Tlajomulco de Zúñiga: CIESAS.

Peralta-Rivero, C., Galindo-Mendoza, M. G., Contreras-Servín, C., Algara-Siller, M., \& Mas-Caussel, J. F. (2016). Percepción local respecto a la valoración ambiental y pérdida de los recursos forestales en la región Huasteca de San Luis Potosí, México Madera y Bosques, 22(1), 71-93. Recuperado en 3 de enero de 2021 de http://www.redalyc.org/articulo.oa?id=61745707005

Rodríguez, G. A. (2020). Lecciones sobre la percepción, exploración y control del territorio y el paisaje Ingeniero de Montes, Cantabria. Sección de Promoción no 132, Segundo Trimestre 2028, p. 51-52. Recuperado en 20 de enero de 2021 de https://www.territoriodecantabria.es/-/lecciones-sobre-la-percepcion-exploracion-y-control-del-territorio-y-el-paisaje

Rojas, C. I. R. (2011). Elementos para el diseño de técnicas de investigación: una propuesta de definiciones y procedimientos en la investigación científica. Tiempo de Educar,12(24). 277-297. Universidad Autónoma del Estado de México Toluca, México. Recuperado en 19 de enero de 2021de http://www.redalyc.org/articulo.oa?id=31121089006

Rosset, P., \& Altieri M. (2019). Principios de la agroecología. En Agroecología: ciencia y política. Serie estudios críticos de desarrollo (p. 23-59). Miguel Ángel Porrúa. 


\section{Percepción del paisaje socioambiental agroecológico}

Sánchez, V. A. (2020). Psicología comunitaria. Definición y bases teóricas: comunidad, desarrollo humano y empoderamiento. Universidad de Barcelona. Recuperado en 1 de febrero de 2021 de https://www.researchgate.net/publication/344648969_PSICOLOGIA_COMUNITARIA_DEFINICION_Y_BASES_TEORICAS_C OMUNIDAD_DESARROLLO_HUMANO_Y_EMPODERAMIENTO_Alipio_Sanchez_Vidal_Universidad_de_Barcelona

Suárez, A. G., García, F. I. \& Cardona, H. L. C. (2020). Metodología de análisis de la percepción ambiental de los niños en una comunidad periurbana. Calarcá, Quindío, Colombia. Sophia, 16(1), 19-32. https://doi.org/10.18634/sophiaj.16v.1i.1004

Tserej, V. O. N., \& Febles, E. M. M. (2013). La escuela cubana como contexto para el correcto desarrollo de la percepción ambiental. Revista Complutense de Educación, 26(1), 31-46. https://doi.org/10.5209/rev_RCED.2015.v26.n1.42335

Editor: Luis Alberto Salinas Arreortua

Recibido: 24 mar. 2021

Aprobado: 13 ago. 2021 